\title{
KAJIAN PENGARUH FASHION DALAM GAME DIGITAL PADA MEDIA SOSIAL FACEBOOK TERHADAP MAHASISWA DIII-SRD UK. MARANATHA (STUDI KASUS: CITY GIRL LIFE)
}

\author{
Dewi Isma Aryani ${ }^{1}$, Irawati Tirtaatmadja ${ }^{2}$ \\ 1,2 Universitas Kristen Maranatha
}

\begin{abstract}
Abstrak: City Girl Life (CGL) adalah sebuah game dengan genre life simulation pada media sosial Facebook yang dikembangkan oleh Rockyou sebagai game developer, sebagai perkembangan dari Disney City Girl (DCG) oleh Disney Playdom. CGL bermula diciptakan pada Desember 2012 dan telah diluncurkan pertama kali pada Januari 2013 dengan format awal yakni DCG. CGL memperlihatkan tentang interaksi sosial yang terjadi antara player dengan pemain lain sebagaimana halnya sistem permainan pada game simulasi fenomenal, The Sims, yang lebih mengutamakan konsep girly di dalamnya. Berbekal desain avatar dan konten baju-baju rancangan desainer terkenal, CGL merupakan game yang menampilkan konsep dan gaya hidup sosialita dengan berbagai aktivitas yang dapat dimainkan seperti profesi fashion designer, celebrity chef, author, musician, dan engineer, yang sedang menjadi tren di kalangan generasi muda dewasa ini. Penelitian mengenai CGL ini ditujukan untuk mengetahui hingga sejauh mana keterikatan pemain game CGL terhadap user interface dan interaksi yang terjadi di dalamnya, serta pengaruh fashion dalam konteks memperkenalkan budaya fashion yang ditampilkan di sepanjang storyline game CGL.
\end{abstract}

Kata Kunci: budaya pop, fashion, game digital, girly, interaksi, simulasi

\begin{abstract}
City Girl Life (CGL) is a life simulation game which can be found on the social media, Facebook, developed by Rockyou as the game developer, as a continueing form of Disney City Girl (DCG) by Disney Playdom. CGL was started in December 2012 and was launched in January 2013 for the first time with DCG form. CGL shows us about the social interraction that occurs between the player with the other players, which similar with the game system at the phenomenal simulation game, The Sims, by using a girly concept in it. Armed with avatars and content of designs dresses from several famous designer, CGL is a game that shows main concept of socialite lifestyle with a variety of activities that can be played as a professional fashion designer, celebrity chef, author, musician, and engineer, which is becoming a trending topics in among young people today. Research on the CGL is intended to determine the extent to which attachment to the CGL game player based on user interface and interactions that occur within it, as well as the influence of fashion culture recognition displayed along the game 's storyline of CGL.
\end{abstract}

Keywords: digital game, fashion, girly, interaction, pop culture, simulation

Penulis adalah pengajar pada Program Studi DIII-SRD Fakultas Seni Rupa dan Desain, Universitas Kristen Maranatha - Jalan Surya Sumantri no 65, Bandung, Indonesia, email: dewiismaaryani@gmail.com 


\section{PENDAHULUAN}

Manusia modern dewasa ini semakin disibukkan dengan bermacam aktivitas yang menyita waktu setiap harinya. Bahkan sebagian besar aktivitas manusia modern dilakukan dengan media bantu elektronik atau digital seperti laptop, tablet, telepon genggam, dan lain sebagainya.

Kehadiran internet disertai dengan adanya perkembangan teknologi pada media komunikasi gadget seperti kemunculan smartphone maupun tablet yang dilengkapi dengan hardware dan software yang semakin mumpuni, selain mempermudah akses internet ke media sosial juga dapat digunakan untuk bermain game. Game digital yang ditawarkan oleh media sosial, seperti Facebook, memiliki variasi yang beraneka ragam dan memiliki user yang tidak terbatas oleh range usia maupun gender. Beberapa game yang ditawarkan media sosial Facebook diantaranya berupa casual game seperti Candy Crush Saga, Texas Poker, Pet Society, Farmville, City Girl Life (dulu: Disney City Girl), Wars of The Clan, dan lain sebagainya. Dari beberapa casual game di atas, game City Girl Life merupakan salah satu game yang mengangkat budaya pop masyarakat Barat dengan menampilkan gaya hidup dan fashion yang sedang tren di negara asalnya, Amerika.

Sebagaimana halnya kebudayaan yang di dalamnya terdapat banyak interaksi, permainan (game) merupakan salah satu wujud nyata dari kebudayaan itu sendiri. Johan Huizinga (1990) dalam bukunya, Homo Ludens - Fungsi dan Hakekat Permainan dalam Budaya, menyatakan bahwa: "Permainan adalah suatu perbuatan atau kegiatan sukarela, yang dilakukan dalam batas-batas ruang dan waktu tertentu yang sudah ditetapkan, menurut aturan yang telah diterima secara sukarela tapi mengikat sepenuhnya, dengan tujuan dalam dirinya sendiri, disertai oleh perasaan tegang dan gembira, dan kesadaran 'lain' daripada kehidupan sehari-hari". 
Game telah menjadi semangat globalisasi dengan menampilkan budaya pop ( $p o p$ culture) berupa pertukaran benda/ simbol, pergerakan antar tempat yang semakin mudah dikombinasikan dengan perkembangan teknologi komunikasi, serta akulturasi kebudayaan. Bermain game, terutama digital game, di zaman modern ini seolah-olah telah meruntuhkan paham konvensional dari game itu sendiri yang secara harfiah memiliki pengertian "permainan". Sejauh mana kemampuan desain grafis yang masih bersifat tradisional dapat ditransformasikan dan dikombinasikan dengan disiplin desain lain melalui suatu media digital dengan sifatnya yang digital, dynamic, dan interactive berupa gaya hidup dan fashion dalam media game akan dikaji lebih lanjut melalui penelitian ini.

\section{KAJIAN TEORI}

\section{Tinjauan Terkait Penelitian Game Sejenis}

Penelitian sejenis telah dilakukan sejak tahun 2000 saat The Sims (simulasi game urban) dan konsep fashion boneka Barbie masuk dalam ranah digital. Maka dari itu, penelitian terkait game Disney City Girl (sekarang berubah nama menjadi City Girl Life) dari aspek psikologi komunikasi yang berhubungan dengan gender stereotypes sudah pernah dilakukan. Namun, penelitian dengan subjek virtual fashion ini dapat dilaksanakan karena termasuk salah satu penelitian yang cukup luas dan kompleks yakni mencakup empat bidang sekaligus: game, digital media, fashion-culture dan anthropology.

Penelitian berjudul "Playing Dress-Up: Costumes, Roleplay and Imagination" yang dilakukan oleh Janine Fron, Tracy Fullerton, Jacquelyn Ford Morie, dan Celia Pearce memaparkan tentang:

Eksplorasi implikasi bermain simulasi dress-up sebagai sarana untuk menciptakan lebih banyak keseimbangan gender dalam budaya permainan, baik di masa sekarang maupun masa depan. Conjoining dress-up yang memiliki daya tarik tinggi dan resonansi budaya bagi perempuan, dengan aspek instrumental dan 
teknis game komputer, dress-up dan roleplay dapat menjembatani batas-batas gender dan stratifikasi yang berlaku dalam budaya kontemporer permainan. Permainan dress-up juga dapat membantu masyarakat untuk lebih memahami budaya pop maupun kontemporer di masa yang akan datang. Terlepas dari jenis kelamin user, permainan dress-up memberikan ekspresi beragam dari aspek kepribadian user.

Oleh karena itu, berdasarkan pemaparan penelitian di atas, maka Penulis melakukan penelitian sejenis dengan studi kasus game City Girl Life untuk mengkaji pengaruh fashion yang ditampilkan dalam game terhadap gaya hidup masyarakat, dalam hal ini terhadap mahasiswa DIII-SRD UK. Maranatha yang mempelajari bidang studi fashion design.

\section{Tinjauan Genre dan User dari Casual Games}

Oxland (2004: 49) dalam buku Gameplay and Design memaparkan tentang kategori pemain game (gamer) berdasarkan unsur keterikatan dari segi waktu bermain, yang dalam positioning tentang game dan player untuk dapat mengkaji lebih lanjut penelitian ini, dibedakan berdasarkan intensitas waktu yang digunakan untuk bermain game yakni hardcore gamer dan casual gamer.

Game City Girl Life mulanya merupakan game dengan gabungan genre Construction and Management Simulations dengan Artificial Life. Game dengan genre construction and management simulations merupakan permainan yang mensimulasikan proyek membangun sebuah kota, pemain diharuskan membangun sebuah kota lengkap dengan fasilitas publik maupun fasilitas pemerintah seperti gedung, alat transportasi publik, taman, sekolah, rumah sakit, tempat beribadah, pabrik, bandara, stasiun, bank, dan bangunan lainnya. Pada saat membangun kota tersebut pemain juga harus memperhatikan sumber daya ekonomi, kenyamanan para penduduknya dalam beraktivitas yang mungkin terganggu saat pembuatan jembatan penyeberangan maupun proyek baru lain yang sedang berjalan. 
Construction and management simulations merupakan genre game yang menitik-beratkan pada proses sepanjang alur ceritanya. Tujuan game ini pun bukanlah mengalahkan musuh seperti pada game-game kebanyakan melainkan pada usaha membangun sesuatu (tergantung konteks game) sebagai suatu proses yang terus-menerus atau kontinyu. Contoh dari genre ini antara lain: SimCity Societies, Farmville, Cityville, Caesar, dan sebagainya.

Game dengan storyline tentang artificial life merupakan game dengan genre simulation. Game semacam ini biasanya mengangkat tema simulasi kehidupan dengan gameplay meliputi kegiatan individu dalam sebuah karakter. Dalam memerankan karakter tersebut pemain bertanggung jawab atas inteligen serta kemampuan fisik dari karakter yang dimainkan layaknya kebutuhan manusia normal seperti: kegiatan belajar, bekerja, belanja, bersosialisasi, memelihara hewan, memelihara lingkungan, dan lain-lain. Lawan main dalam game ini bisa berupa pemain lain yang memainkan karakter sebagai tetangga maupun komputer dengan kecerdasan buatan (artificial intelligence). Contohnya adalah SimLife, Second Life, Harvest Moon.

Berdasarkan definisi di atas, maka pembatasan user atau player yang akan digunakan untuk mengkaji studi kasus dalam penelitian mengenai game City Girl Life lebih lanjut adalah ditinjau dari sisi casual gamer dengan konsentrasi pada genre construction and management simulations sekaligus artificial life yang pada akhirnya menjadi lebih spesifik ke arah urban game simulation.

\section{Tinjauan Tentang Karakter, Visual dan Teori Yang Digunakan Dalam Penelitian}

Yang dimaksud dengan karakter menurut Kamus Besar Bahasa Indonesia adalah suatu peran yang dijalankan atau diperagakan oleh seseorang dalam suatu pementasan cerita, drama, dan sebagainya di panggung, radio, televisi, atau film dan berhasil dengan baik.

Pengertian dari game character secara umum adalah merujuk pada karakter atau peran itu sendiri, memiliki sifat atau pembawaan unik dan khusus 
yang melekat pada suatu objek tertentu, seperti yang dipaparkan Schell (2008: 309-328) mengenai fungsi-fungsi karakter yang terdapat dalam game berdasarkan genre-genre yang ada. Game character dapat dibagi ke dalam 3 kategori besar berdasarkan kapasitas gameplay suatu game yakni: player character, non-player character, dan secret character. Player character merupakan karakter dalam suatu game yang dapat dimainkan. Player character dapat dijumpai hampir di seluruh genre game yang ada untuk dimainkan.

Yang dimaksud dengan visual dalam tulisan ini adalah berupa grafis sebagai salah satu elemen game, selain suara (sound), tampilan antarmuka (interface), aturan permainan (gameplay), dan cerita (story), sebagaimana yang dipaparkan oleh Newman (2004: 11). Dengan demikian, pengertian game menurut Newman dapat diartikan sebagai suatu permainan yang di dalamnya terkandung elemen game seperti grafis, suara, tampilan antarmuka, aturan permainan dan cerita.

- Grafis (Graphics)

Grafis merupakan segala gambar maupun efek yang ditampilkan dan diterapkan dari suatu objek. Grafis yang dimaksud meliputi objek 2D, objek 3D, tayangan video (Full Motion Video), statistik, jendela informasi dan segala sesuatu yang dapat terlihat oleh mata pemain.

- Suara (Sound)

Yang dapat digolongkan ke dalam sound adalah segala musik atau efek suara yang dimainkan selama permainan berlangsung.

Elemen suara yang dimaksud meliputi musik pembuka, efek suara maupun musik pengiring dalam lingkungan permainan.

- Tampilan antarmuka (Interface)

Yang dimaksud dengan interface adalah segala sesuatu yang digunakan pemain ketika melakukan kontak untuk mengontrol permainan, termasuk perangkat keras seperti: keyboard, mouse, dan joystick. Selain perangkat 
keras, interface juga meliputi tampilan grafis yang harus diaktifkan oleh pemain, sistem menu, dan lain sebagainya yang berhubungan dengan interaksi pemain.

- Aturan Permainan (Gameplay)

Gameplay merupakan suatu aturan dalam permainan yang dapat menunjukkan seberapa menyenangkan, menarik dan seberapa lama (longevity) permainan itu dapat dimainkan. Pengertian gameplay menurut Oxland (2004:7) adalah sebagai berikut:

"Gameplay is the component that make up a rewarding, absorbing, challenging experience that compels the player to return for more, time and time again".

- Cerita (Story)

Cerita dalam game adalah segala sesuatu yang menjadi latar belakang kejadian dan informasi sepanjang permainan berlangsung hingga permainan berakhir atau tamat yang ditampilkan secara runut.

Visualisasi karakter dalam game tidak luput dari proses industrialisasi budaya yang diproduksi secara massal serta memiliki imperatif komersial. Akibatnya proses yang berlangsung di dalamnya, terkait dengan hal ini adalah industri game, adalah proses komodifikasi, standardisasi, serta masifikasi.

Proses komodifikasi memiliki pengertian tentang proses perlakuan produk-produk budaya sebagai komoditas yang bertujuan akhir untuk diperdagangkan. Faktor komodifikasi yang ada dalam game adalah konten dari game itu sendiri yang sekaligus menjadi faktor reproduksi ulang dari sesuatu yang sebelumnya sudah pernah dibuat.

Standardisasi berarti suatu proses penetapan kriteria tertentu yang memudahkan produk-produk suatu industri budaya mudah dicerna oleh khalayaknya. Standardisasi dalam game tidak hanya terdapat pada unsur 
gameplay yang menarik atau fun melainkan juga menurut standar nilai kepatutan tertentu yang biasa dikenal dengan istilah rating oleh lembaga khusus.

Sedangkan pengertian masifikasi berarti suatu proses produksi berbagai hasil budaya dalam jumlah massal agar dapat meraih pangsa pasar seluasluasnya. Dalam sebuah industri game, masifikasi ditentukan salah satunya melalui gameplay suatu game itu sendiri. Apabila terdapat faktor fun di dalamnya, maka akan mampu menjadikannya sebagai suatu komoditas dengan nilai jual yang tinggi.

\section{METODE PENELITIAN}

Metode yang digunakan dalam penelitian ini adalah metode kualitatif. Metode pengumpulan data dibagi dalam beberapa tahap, yaitu:

1. Tahap I, merupakan tahap studi literatur mengenai game secara umum, yang akan menjadi rujukan untuk tahap selanjutnya, yakni casual game.

2. Tahap II, merupakan studi literatur mengenai fashion, pop-culture dan lifestyle yang dipilih untuk diangkat menjadi topik kajian penelitian yakni mengenai game yang berjenis casual game.

Metode analisis data meliputi:

1. Tahap analisis menggunakan pendekatan deskriptif-analisis dengan memaparkan secara rinci latar belakang konseptual, teori komunikasi yang dibangun serta gameplay yang mendasari terciptanya game untuk memperkenalkan fashion dan pop-culture sebagai salah satu lifestyle masyarakat modern.

2. Tahap eksplanasi, sebagai tahap penjelasan dan kesimpulan dari negosiasi yang terjadi antara konsep pemikiran dalam penelitian dan diharapkan dapat diwujudkan ke dalam suatu perancangan game berdasarkan tahapantahapan yang telah dilakukan sebelumnya. 
Berdasarkan pemaparan metode penelitian dan analisis data di atas, maka melalui penelitian ini akan diidentifikasi pencapaian yang diharapkan berupa:

1. Sebagai sarana untuk dapat mengetahui relasi antara konsep visual, teori komunikasi dan sistem gameplay dalam proyek penelitian "Kajian Pengaruh Fashion Dalam Game Digital Pada Media Sosial Facebook Terhadap Mahasiswa DIII-SRD UK. Maranatha (Studi Kasus: City Girl Life)" yang memfasilitasi proses permainan sekaligus mengkaji tentang popculture yakni budaya fashion yang sedang tren.

2. Sarana untuk dapat memahami relasi visualisasi karakter game dikaitkan dengan tingkat leveling pola, building system dari interaksi berdasarkan gameplay, model sistem gameplay, dan alur cerita dalam permainan game sebagai bagian dari pembelajaran budaya fashion.

3. Sarana untuk dapat memberikan kontribusi dan hasil akhir yang diharapkan, baik subyek maupun obyek, yakni memperkenalkan tentang budaya fashion kepada masyarakat dengan adanya penelitian "Kajian Pengaruh Fashion Dalam Game Digital Pada Media Sosial Facebook Terhadap Mahasiswa DIII-SRD UK. Maranatha (Studi Kasus: City Girl Life)" ini.

\section{HASIL DAN DISKUSI}

\section{Temuan Umum}

Gaya hidup secara umum dapat diartikan sebagai suatu kegiatan yang dikenali dengan bagaimana orang menghabiskan waktunya (aktivitas), apa yang penting orang pertimbangkan pada lingkungan (minat), dan apa yang orang pikirkan tentang diri sendiri dan dunia di sekitar (opini).

Berdasarkan data-data survey dan pengamatan yang dilakukan penulis terhadap beberapa responden diperoleh data-data sebagai berikut:

1. Pekerjaan

Beberapa responden yang memiliki status aktif bekerja cenderung menghabiskan waktunya di depan laptop ataupun PC ketika berada di 
tempat kerja. Sebagian besar pekerjaan berkaitan dengan tingkat pendidikan yang dapat mempengaruhi cara berfikir terhadap permasalahan fisik, sosial, kebiasaan, dan perilaku.

2. Pendidikan

Secara keseluruhan pendidikan responden diperoleh secara formal maupun non-formal. Hal ini akan banyak memberikan pengaruh terhadap cara berfikir, bersikap maupun bertingkah laku dan tercermin dalam kehidupan sehari-hari. Berdasarkan hasil tersebut dapat dikatakan bahwa responden dengan tingkat pendidikan yang tinggi memiliki pola pikir serta pemahaman lebih baik dalam menyikapi permasalahan tertentu.

3. Hobi

Beberapa responden yang menyukai game City Girl Life sebagian besar ber-gender perempuan dan memiliki hobi/ minat yang berhubungan dengan fashion dan aksesoris.

Hal tersebut di atas tentunya tidak lepas dari pengaruh gaya hidup (lifestyle) masyarakat. Bagi beberapa masyarakat golongan menengah ke atas cenderung telah memiliki kesadaran tinggi terhadap mode dan busana (fashion awareness) sehingga seolah-olah menjadi sebuah keharusan untuk memperhatikan totalitas dalam berpenampilan. Hasil temuan lain terhadap pengamatan responden dalam menyikapi permasalahan fashion dan lifestyle terletak pada kebiasaan pemilihan jenis busana maupun aksesoris yang dikenakan sehari-hari. Warna dan desain aksesoris yang dikenakan tersebut tidak hanya sekedar elemen estetis melainkan juga memberikan pemahaman suatu makna pada maksud desain aksesoris itu sendiri.

\section{Keterkaitan Antara Fashion, Pop-Culture, dan Lifestyle}

Game City Girl Life menampilkan unsur fashion, pop-culture dan lifestyle yang kuat sepanjang storyline yang dapat dimainkan oleh player. Unsur fashion yang ada dalam game ini merupakan kategori high fashion 
yakni fashion yang merupakan hasil rancangan desainer kenamaan dunia, sehingga tidak dipungkiri lagi bahwa hal ini menjadi daya tarik game CGL yang menampilkan pop-culture dan lifestyle kota metropolitan. Suasana metropolitan yang ditampilkan dalam game CGL ini adalah kota New York, dikenal sebagai salah satu kota pusat mode dunia dan terdapat banyak rumah mode terkenal seperti DKNY (Donna Karan New York), dan lain sebagainya. Dengan demikian, sangat tepat dikatakan jika game CGL mengangkat tema fashion, pop-culture, dan lifestyle sekaligus dalam storyline permainannya dan kombinasi unsur tersebut mampu menjadi daya tarik dan meningkatkan curiousity pemain untuk terus mengikuti alur cerita yang disajikan.

\section{Pengaruh Fashion Awareness Terhadap Masyarakat Kota Bandung}

Keberadaan beberapa program tayangan di televisi maupun rubrik yang membahas tentang tren dan fashion dewasa ini turut meningkatkan adanya fashion awareness di kalangan masyarakat. Program tayangan maupun rubrik tentang fashion yang ditampilkan tersebut sebagian besar dipengaruhi oleh gaya hidup dan tren terbaru berasal dari sosialita maupun public figure, contohnya Hollywood maupun Korea Selatan yang memberikan kesan glamor atau mewah. Beberapa infografis yang menampilkan fashion awareness juga turut mewarnai media sosial, dalam hal ini adalah Pinterest maupun blog pribadi fashion blogger. Fashion awareness yang ditampilkan melalui infografis tersebut diharapkan dapat lebih mudah diterima dan dipahami oleh masyarakat, karena informasi yang ditampilkan merupakan hasil dari survey maupun riset dengan kredibilitas baik dan terpercaya oleh lembaga maupun produk sponsor tertentu terhadap tren yang sedang terjadi.

Dengan demikian, adanya fashion awareness yang cukup baik di kalangan masyarakat dapat turut menjadi sebuah referensi bagi masyarakat di Kota Bandung pada umumnya dan mahasiswa DIII-SRD Universitas Kristen 
Maranatha pada khususnya, untuk dapat menampilkan citra positif pada Kota Bandung sebagai kota kreatif dengan potensi sumber daya manusia kreatif terbesar. Hal ini didukung dengan fakta bahwa sejak dulu Bandung telah dikenal sebagai pusat tekstil, mode, seni, dan budaya dengan sebutan "Paris van Java". Apalagi dengan terpilihnya Kota Bandung sebagai pilot project kota kreatif se-Asia Timur di Yokohama 2007, maka diciptakan slogan "Bandung Creative City" guna mendukung misi tersebut telah menjadikan Kota Bandung sebagai salah satu daerah tujuan wisata (http://dppk.bandung.go.id/berita/detail/31 diakses 16 Agustus 2015 pukul 19.57 WIB).

\section{Temuan Khusus}

Berdasarkan hasil interview kepada beberapa responden mengenai wawasan tentang fashion, pop-culture, dan lifestyle yang ada dalam game City Girl Life, beberapa jawaban yang diberikan responden menunjukkan tentang pengertian dan pemahaman yang cukup baik terhadap ketiga hal tersebut serta dampak yang ditimbulkannya. Indikasi yang dimaksud adalah adanya upaya oleh beberapa responden yang ada di lingkungan kampus, dalam hal ini adalah mahasiswa DIII-SRD, melalui deskripsi mengenai beberapa objek studi yang dikaji dalam penelitian ini.

\section{Logo Game}

Awalnya game yang diangkat dalam penelitian ini bernama Disney City Girl sebagai salah satu jenis social game yang dapat dimainkan secara online di media sosial Facebook oleh pengembangnya, Disney Playdom, pada Desember 2012 dan resmi dirilis pada 17 Januari 2013. Sebagai game yang menitikberatkan pada alur life simulation, para pemain berperan sebagai seorang gadis yang baru saja menyelesaikan kuliahnya dan pindah ke kota besar, New York, untuk mengejar impiannya. Secara sekilas game ini mengingatkan pada game sejenis, The Sims, dengan pemain yang dapat 
dipilih perannya (pria atau wanita) untuk mengikuti kegiatan sehari-hari sebagaimana storyline yang ada dalam game.

Disney City Girl cukup sukses dimainkan secara online di media sosial hingga akhirnya mengalami proses pergantian pengembangan game kepada developer lain yakni Rockyou. Walaupun mengalami fase pergantian developer, namun game ini tidak mengalami perubahan besar. Hal ini dapat diamati pada logo yang digunakan, baik pada saat bernama Disney City Girl (Disney Playdom) maupun setelah berubah nama menjadi City Girl Life (Rockyou). Berikut ini adalah perubahan logo yang dimaksud:

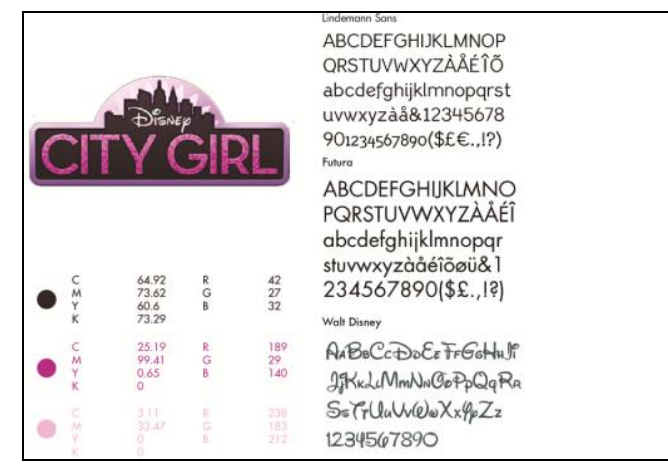

Gambar 1. Logo Disney City Girl

(Sumber: Dok.pribadi, 2015)

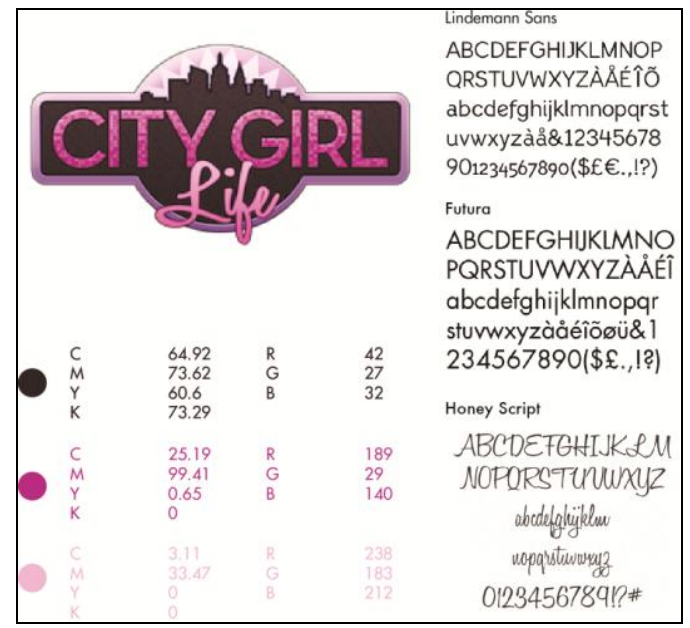

Gambar 2. Logo City Girl Life

(Sumber: Dok.pribadi, 2015) 
Logo game yang ditunjukkan oleh gambar di atas terkait penggunaan warna dan font utama sebagai identitas game tidak mengalami perubahan yang signifikan. Dari segi penggunaan warna, kedua logo masih mempertahankan tone warna yang sama. Sedangkan penggunaan font pada logo hanya terdapat perubahan pada kata "Disney" yang menggunakan font Walt Disney menjadi “Life” dengan font Honey Script.

Secara keseluruhan, garis besar bentuk logo game CGL terdiri atas perpaduan bentuk persegi panjang dan lingkaran, sehingga memberikan kesan kokoh dan stabil sebagai dasar berpijak dari siluet gedung-gedung dari kejauhan membentuk tampilan garis cakrawala sebuah kota. Sedangkan bentuk lingkaran mewakili kesan dinamis seperti halnya kehidupan gadis remaja perkotaan yang ditampilkan sepanjang storyline game CGL. Bentuk segitiga ditampilkan oleh pendar cahaya yang melengkung di bagian atas gedung dengan pewarnaan font City Girl menyerupai kerlip lampu-lampu billboard di atas warna hitam pekat, identik layaknya kehidupan di kota-kota besar. Bentuk font pada kata Life sangat menunjang kesan dinamis logo dan sebaliknya font pada City Girl yang sederhana dan kaku lebih mengikat kesatuan seluruh penampilan logo.

Perubahan jenis font yang dipakai tersebut menjadi indikasi pergantian game developer yakni dari Disney Playdom (dengan penggunaan font Walt Disney pada kata "Disney") kepada Rockyou (dengan penggunaan font Honey Script pada kata "Life"). Namun, secara umum kedua jenis font tersebut memiliki kategori yang sama yakni berhuruf script menyerupai goresan tangan yang dikerjakan dengan pena, kuas, atau pensil tajam dan biasanya miring ke kanan. Selain itu, penggunaan font script pada logo game merupakan salah satu identitas yang ingin disampaikan pada game ini yakni adanya unsur feminitas yang sangat kuat. 


\section{Unsur Fashion Dalam Game}

Unsur fashion yang ditampilkan di dalam game ini dapat dikategorikan sebagai berikut:

Tops: shirts, dresses, underwear

Bottoms: pants, skirts, dresses, underwear

Footwear: shoes, hosier

Accessories: glasses, gloves, purses

Appearance: hair, skin, eyes, eyebrows

Make-up: eyeshadow, lips, blush

Pembagian kategori fashion di atas berdasarkan pada karakteristik fashion yang ada dalam konteks runway (peragaan busana di catwalk), baik haute couture maupun ready to wear deluxe hingga fashion yang bersifat casual to wear dalam keseharian masyarakat. Selain itu, kategori di atas juga sangat aplikatif dan dapat disesuaikan sesuai kebutuhan user dalam berbagai situasi dan event tertentu.

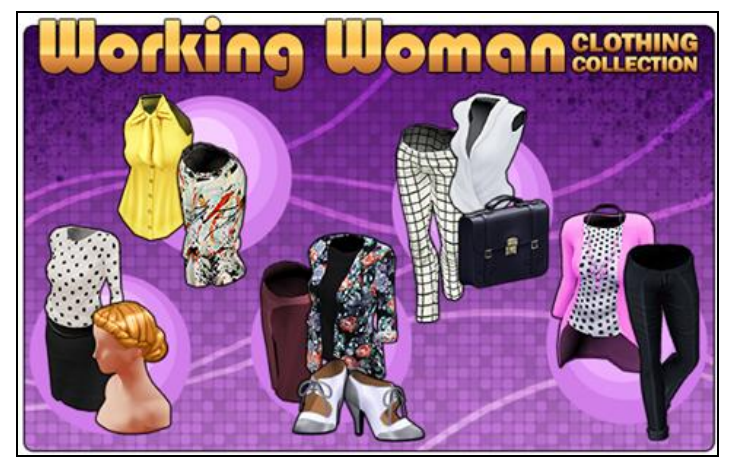

Gambar 3. Salah satu tema fashion dalam City Girl Life (Sumber: http://rockyou.com, 2015)

Unsur fashion yang ditampilkan dalam permainan ini beberapa diantaranya dapat diperoleh melalui event yang terjadi dalam game ataupun melalui purchasing, sebagaimana layaknya aktivitas jual beli dalam game dengan genre social game seperti City Girl Life yang sangat kuat unsur 
interaksi sosial di dalamnya. Dalam unsur fashion yang ditampilkan dalam game ini juga menampilkan berbagai jenis style fashion pada umumnya yakni: everyday, nightlife, professional, activewear, costume.

\section{Pengaruh Fashion Dunia Dalam Game City Girl Life}

Beberapa pemaparan mengenai fashion pada sub-bab sebelumnya digunakan sebagai landasan dalam kajian terkait pengaruh fashion dunia dalam permainan ini. Sebagaimana perkembangan dunia fashion di tanah air tidak lepas dari pengaruh fashion dunia yang diciptakan oleh para desainer terkenal seperti: Donna Karan, Kate Spade, maupun Carolina Herrera. Berikut ini akan Penulis tampilkan beberapa temuan unsur fashion dalam game CGL yang mengadaptasi fashion dari para desainer dunia maupun fashion house ternama lainnya.

Berikut akan dipaparkan mengenai temuan yang dimaksud oleh Penulis dalam game CGL terkait pengaruh fashion dunia:

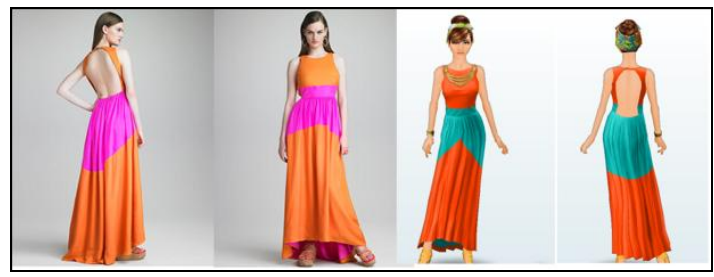

Gambar 4. Pengaruh fashion City Girl Life: Tibi (Sumber: dok.pribadi, 2015)

Fashion yang ditampilkan dalam gambar di atas termasuk kategori fashion everyday dalam game CGL, merupakan hasil desain oleh Tibi pada spring 2013. Brand Tibi sendiri didirikan di New York merupakan hasil rancangan desainer, Amy Smilovic, dengan inspirasi budaya lokal dan kainkain etnik Hongkong. Dress rancangan Amy memberikan kesan feminin, modern namun tetap terlihat santai, potongan unik melalui tampilan warna berani dan kaya akan corak. 
Apabila diperhatikan lebih detil, sekilas dress yang ditunjukkan gambar 4 di atas memiliki pola seperti "peplos" yakni sehelai kain lebar yang tersusun terlipat dan dikenakan menjadi baju melalui proses lilitan, ikatan, dan sematan seperti halnya pakaian bangsa Yunani Kuno. Hal tersebut tampak pada ikatan pinggul (kolpos) yang menerapkan sistem karet/ kolor dan susunan kerut melingkar di badan. Namun, potongan asimetris dari dress di atas pada bagian belakang punggung yang terbuka menjadi focal point dari dress yang berkesan etnik tersebut.

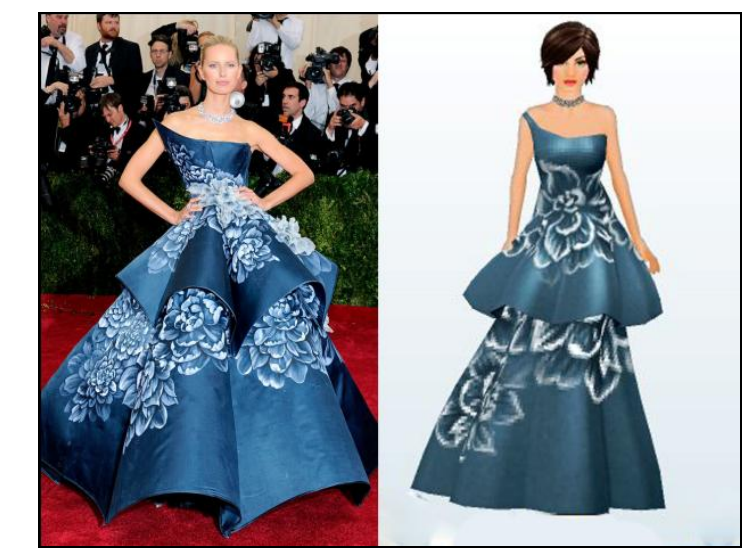

Gambar 5. Pengaruh fashion City Girl Life: Marchesa (Sumber: dok.pribadi, 2015)

Fashion yang ditampilkan dalam gambar di atas termasuk kategori fashion nightlife dalam game CGL, merupakan hasil desain oleh Marchesa pada spring 2014. Marchesa merupakan fashion brand terkemuka yang didirikan pada tahun 2004 oleh Georgina Chapman and Keren Craig dengan paradigma desain couture dan eveningwear. Ciri khas desain Marchesa adalah gaun dengan tampilan feminin atau bertema peri, memiliki detil halus yang dijahit tangan dan biasanya menggunakan aksen kristal, renda, maupun tali-tali rumit berhiaskan manik-manik. 
Gambar 5 di atas menampilkan gaun Marchesa yang dikenakan oleh Karolina Kurkova pada acara red carpet Met Gala 2014 di New York. Gaun Marchesa tersebut memiliki siluet unik, anggun, glamor dalam teal rona warna biru dengan motif prin bunga Painterly, pola potongan, dan bentuk dramatis structured dilengkapi dengan perhiasan berlian desain Harry Winston. Struktur dramatis yang dimaksud adalah memiliki image seperti payung yang mengembang.

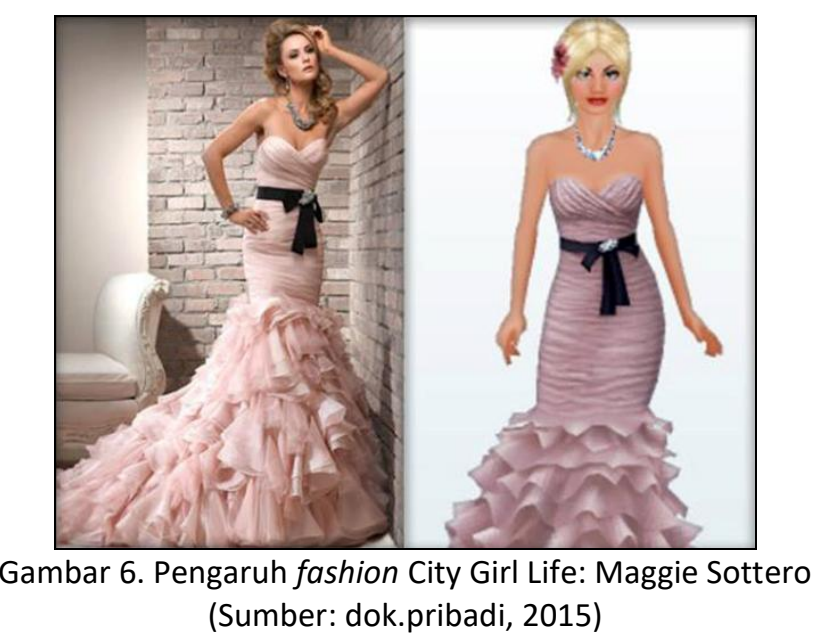

Fashion yang ditampilkan dalam gambar di atas termasuk kategori fashion nightlife dalam game CGL, merupakan hasil desain oleh Maggie Sottero pada fall 2012. Maggie Sottero merupakan desainer gaun pengantin tingkat dunia yang selalu menampilkan desain yang klasik, kontemporer, romantic, chic, dan glamor di setiap rancangannya. Semua gaun pengantin rancangannya menggunakan material kain berkualitas tinggi dan konstruksi yang unggul, fokus pada setiap detail karena bersifat custom dan handmade yakni dijahit dengan tangan untuk setiap hiasan, seperti Swarovski untuk aksen Kristal dan juga detil pada finishing. Gaun rancangan Maggie Sottero menampilkan kesan vintage yang terinspirasi dari era neo-klasik, aksen drop waist dari era art deco, sarung slinky dan manik-manik yang rumit dari era art nouveau. 
Pada gambar 6 di atas tampak sebuah gaun wedding dalam warna opal organza yang menawan dengan aksen memerah untuk pengantin modern, atau putih gading untuk tampilan pengantin yang lebih tradisional. Sebuah korset asimetris ruched ketat di bagian pinggang memberikan tampilan seperti putri duyung hingga melalui bagian pinggul dan terurai menjadi rok berlapis. Pada bagian pita ikat pinggang dihias dengan motif manik-manik kristal Swarovski, selaras dengan kalung yang dikenakan oleh model maupun karakter dalam game CGL.

\section{KESIMPULAN DAN SARAN}

Berdasarkan hasil pembahasan sebelumnya, maka dapat ditarik kesimpulan sebagai berikut:

- Konsep desain busana dalam game sebaiknya memberikan image yang baik/ positif dari desainer terkait. Sehingga diharapkan mampu memberikan dorongan kognitif dan persuasif bagi masyarakat untuk menghargai orisinalitas karya desain, dalam hal ini ditujukan kepada mahasiswa DIII-SRD.

- Desain busana yang ditampilkan dalam game sebaiknya dilengkapi dengan informasi detil mengenai busana terkait, material, perancangnya, event pertama busana tersebut ditampilkan di hadapan publik/ publikasi, dan lain sebagainya sehingga melalui game dapat menjadi sumber alternatif informasi/ wawasan kepada masyarakat, dalam hal ini ditujukan kepada mahasiswa DIII-SRD.

- Salah satu unsur dalam desain (seni rupa) adalah warna, selain unsur rupa/ bentuk. Jadi, sudah sewajarnya desain yang "baik" memiliki kedua unsur tersebut sebagai bagian dari dorongan kognitif (pembelajaran) manusia sebagai user utamanya. Dalam game CGL ini melibatkan 
beberapa unsur desain di dalamnya seperti desain interior, desain fashion, desain produk, dan juga desain grafis.

- Pemahaman terhadap warna memiliki makna yang berbeda-beda, sehingga penggunaannya dalam desain perlu mendapatkan perhatian dan kajian lebih lanjut (faktor psikologis). Dalam hal ini pada beberapa desain busana yang memiliki model serupa namun berbeda warna.

- Desain yang baik harus mempertimbangkan faktor long life cycle (siklus hidup) sejak tahapan produksi dilakukan sampai pada tahapan postproduction untuk memberikan kemudahan user dalam proses perawatan (maintenance). Dalam hal ini adalah banyaknya event-event dalam game CGL yang dapat menimbulkan high-curiosity kepada pemain untuk terus memainkan permainan.

- Dunia fashion sudah menjadi bagian gaya hidup dan mempengaruhi gaya setiap orang dalam kesehariannya. Perubahan gaya hidup yang terjadi di kalangan mahasiswa salah satunya disebabkan adanya penggunaan internet sebagai salah satu sarana sumber informasi, media sosialisasi dan aktualisasi diri, mencari pekerjaan, mencari uang, dan lain sebagainya. Melalui game CGL, pemain dapat melakukan aktivitas tersebut dengan pemain lainnya terutama mendapatkan informasi terbaru tentang perkembangan dunia fashion sehingga dapat menjadi literatur alternatif mata kuliah mayor fashion design bagi mahasiswa DIIISRD.

- Adanya internet sangat berguna untuk koneksi komunikasi dan penyebaran informasi secara global, salah satunya adalah melalui game CGL. Dengan demikian, semakin majunya sistem teknologi (internet) dan komunikasi maka mengakibatkan perubahan sosial berkembang dengan cepat. 
- Fashion merupakan salah satu topik pembicaraan yang paling sering dibahas oleh mahasiswa. Perkembangan fashion Indonesia dan dunia saat ini sangat pesat. Melalui game CGL, diharapkan mahasiswa DIII-SRD dapat mengetahui informasi terbaru dari dunia fashion sekaligus menjadi referensi dalam berkarya selama menempuh studi.

Game CGL merupakan salah satu social game yang mengangkat topik fashion sebagai storyline utamanya. Konten pop-culture dan lifestyle menjadi daya tarik pendukung game CGL ini sehingga dapat memberikan informasi kepada pemain melalui cara yang menyenangkan untuk belajar. Indikasi yang dimaksud adalah adanya upaya yang dilakukan oleh beberapa responden, dalam hal ini adalah mahasiswa DIII-SRD, melalui deskripsi mengenai konten fashion, pop-culture, dan lifestyle yang dikaji dalam penelitian ini. Diharapkan di masa yang akan datang, game dapat menjadi referensi alternatif sebagai media informasi kepada masyarakat.

\section{DAFTAR PUSTAKA}

\section{Literatur}

Huizinga, Johan. 1990. Homo Ludens - Fungsi dan Hakekat Permainan dalam Budaya (terj. Hasan Basari). Jakarta: Penerbit LP3ES.

Kamus Besar Bahasa Indonesia (Edisi Ketiga). 2002. Jakarta: Balai Pustaka.

Oxland, Kevin. 2004. Gameplay and design. Addison Wesley.

Newman, James. 2004. Videogames. London: Routledge.

Schell, Jesse. 2008. The Art of Game Design: A Deck of Lenses - Cards.

\section{Artikel online}

Kim, John H., 2003. Story and Narrative Paradigms in Role-Playing Games. Diposting pada hari Rabu, 29 Oktober 2003 pukul 10:18:18 di 
http://www.darkshire.net/ jhkim/rpg/theory/liz-paper-2003/. (diakses pada 11 Februari 2015 pukul 16:08 WIB).

https://www.bestbridalprices.com/maggie-sottero-wedding-dresses-c1d103

(diakses 4 November 2015 pukul 11.24 WIB).

http://www.redcarpet-fashionawards.com/2014/05/06/karolina-kurkova-

marchesa-2014-met-gala/

(diakses 9 November 2015 pukul 15.44 WIB).

(http://dppk.bandung.go.id/berita/detail/31 diakses 16 Agustus 2015 pukul 19.57 WIB).

http://rockyou.com, 2015) 